\title{
Using Open-source Learning Management Systems (LMSs) in the Egyptian Undergraduate English as a Foreign Language (EFL) Class: A Case Study Addressing Economically Disadvantaged Countries
}

\author{
Maha El-Batanouny ${ }^{1}$, Ranya Elkhayat ${ }^{2}$, Hend Elsheikh $^{1}$ \\ ${ }^{2}$ University of Glasgow, UK, ${ }^{1}$ Zewail City, Egypt
}

\begin{abstract}
EFL teachers striving to use technology to facilitate learning and teaching in economically disadvantaged countries suffer from the scarcity of funds to buy/subscribe to commercial LMSs. Accordingly, in order to facilitate the use of LMSs in such countries, this case study aims to present a generic rubric to assist EFL instructors in choosing an open-source LMS exemplified in Google Classroom (GC) and Canvas (C). This comparison is based on a one-year hands-on experience of using the two LMSs in the undergraduate English Language Program in a higher education institution in Egypt. The rubric includes five main criteria: (1) class and group management, (2) content management, (3) assessment and feedback, (4) communication, collaboration, and synchronization, and finally, (5) capacity. The comparison revealed how $C$ surpassed $G C$ in class and group management, assessment and feedback, and communication, collaboration and synchronization whereas GC took precedence over $C$ in capacity and content management. Even though both LMSs showed advantages and disadvantages, they both saved the teacher's class time and facilitated communication and feedback outside class. This paper guides EFL teachers in economically disadvantaged countries to choose the best opensource LMS based on the proposed criteria, saving both their time and effort.
\end{abstract}

\section{Introduction}

Information technology revolutionized the field of education, aiding in the enhancement of Blended Learning (BL) in higher education. BL refers to leveraging the digital content and integrating different delivery modes, teaching models, and learning styles to cater for monitored individualized, self-paced learning [1]. LMSs became part and parcel of BL roughly in 2007 [2]. Numerous LMSs were introduced in both open-source and commercial forms such as Moodle, Blackboard, Desire2learn, Canvas and more recently, Google Classroom. Higher education institutions in emerging economies struggle to employ commercial LMSs, which may affect teaching and learning processes. With largesize, mixed-ability classes and different learning styles hindering teaching effectiveness, the EFL class is no longer a one-pace-fits-all lecture for all EFL learners. Whether the EFL instructor chooses to adopt behaviourism, cognitivism, constructivism, and/or connectivism as a learning theory, there stands the need for open- source LMSs in assisting practitioners in implementing different BL models in the EFL classroom.

LMSs provide a wide array of features for learning and instruction. Not only is an LMS a convenient tool for messaging and providing a gradebook, it also facilitates interaction, evaluation and course content management [3]. It evaluates both student and organizational goals and tracks student progress [4]. Moreover, such an interface allows sharing material by both students (Ss) and teachers (Ts), and posting announcements [5]. Other features include group work, assignment comments, synchronous or asynchronous activities.

These features are updated regularly by LMS developers to meet the needs of Ts and Ss and, hence, have the potential to improve motivation, guided practice, interaction, engagement, personalized learning, inquiry-based learning, collaboration, and project-based learning. Using JUSUR LMS in Saudi Arabia, [6] proved the effectiveness of BL in enhancing three different types of interaction: student-teacher, student-student, student-material/content; in return, these various types of interaction improved the speaking skill of the experimental group participating in synchronous and asynchronous speaking activities. The author concluded by accentuating the necessity for the EFL classroom to become more flexible to allow communication outside the classroom walls and called for e-learning professional development training sessions for EFL Ts. Such a recommendation falls within the scope of the present study that presents an easy and cost-effective tool Ts can tailor to enhance BL.

Despite all these advantages, an investigation into the Ts' and learners' perceptions of and attitude towards BL is of crucial importance. For example, in 
an attempt to determine EFL Indonesian Ss' perceptions of face-to-face teaching mode in comparison to online lessons, [7] used quantitative and qualitative open-ended questions with more attention directed at motivation and interest. The overall scores reflected how a higher number of Ss associated face-to-face classes with higher motivation as a result of better understanding, peer and $\mathrm{T}$ interaction, and the direct and live provision of EFL input. Ss favouring online classes justified their preference depending on convenience, speed, and time and place flexibility. In the end, Wright recommended how a skillful implementation of BL can boost an EFL course without forsaking the importance of face-to-face teaching. In the same line of research, [8] investigated the EFL sophomores' perceptions of an LMS-supplemented one-semester English course, with 32 hours contact hours. Pre- and post-anonymous surveys were used to trace the development of the learners' willingness to use BL in learning English. Results reflected a notable evolution in their attitudes towards using BL in EFL classroom. The percentage of those admitting the usefulness of LMS increased significantly from $27 \%$ to $63 \%$, evidence showing how the learners completed the course with positive perceptions towards LMS learning.

In an attempt to investigate the perceptions of 50 male Ss using Blackboard in the English courses at Al Jouf University (Kingdom of Saudi Arabia), [9] found that it assisted them in learning at their own pace, especially in problematic language areas. Furthermore, pedagogically, Blackboard did not only provide various tools such as quick feedback, skill building, and improved communication in the BL instruction but further created a motivational learning environment. However, they found that the learners were neutral about Blackboard providing an interesting and lively environment, but this could be attributed to the early stage of application in addition to the lack of awareness of the benefits of Blackboard. This justifies why they recommended longitudinal research to see if such an attitude may change over time and to include female participants.

In conclusion, most studies investigating learner attitude towards the LMS-supported EFL classes did not focus on the criteria a teacher should focus on while selecting an open-source LMS to enhance BL, especially in financially disadvantaged countries, except Ramesh and Ramanathan [10], whose study is replicated and adapted here to suit the EFL classrooms in underprivileged countries. The current research draws attention to the use of free LMSs in EFL teaching in higher education by aiming to present a generic rubric to assist EFL instructors in choosing an open source LMS exemplified in Google Classroom (GC) and Canvas (C). This comparison is based on a one-year hands-on experience of using the two LMSs in the undergraduate English
Language Program at a higher education institution in Egypt.

\section{Methodology}

Ramesh and Ramanathan's replicated research study was conducted in India. Using a set of criteria relevant to the needs of an engineering higher education institution, they aimed to evaluate Moodle and Sakai, two open-source LMSs. The present case study, however, proposes the criteria of a more generic rubric as a result of the researchers' own experience using both $\mathrm{GC}$ and $\mathrm{C}$ for one academic year.

The research participants were three English instructors and course coordinators who worked closely with both the EFL courses' Ts and Ss, providing a bird's eye view of the creation, monitoring and evaluation of the English courses and their final outcomes. Eighty-five Ss were enrolled in $\mathrm{C}$ and 25 were enrolled in GC. The English courses under study focused mainly on productive language skills (speaking and writing). The writing sections were the most essential for LMS use because all the writing assignments had to be uploaded by the student and graded by the teacher and be visible to the coordinator.

The criteria of the rubric were chosen based on the most essential factors for an English language course. The rubric comprises five essential criteria: (1) class and group management, (2) content management, (3) assessment and feedback, (4) communication, collaboration, and synchronization, and finally, (5) capacity. Each item and subitem in the criteria was evaluated using a 1-5 Likert scale to measure involved Ts' attitudes and perceptions, 1 being the least beneficial and 5 being the most beneficial.

\subsection{Class and group management}

This main criterion entails the ease of creating classes at the beginning of the semester. It is divided into the subcategories of creating a class and adding/ removing Ss, adding sub-groups or sections for each course, adding co-teachers or teaching assistants, tracking attendance for the benefit of both Ts and Ss, sending notifications, and having a course calendar to highlight important dates or assignment due dates.

\subsection{Content management}

In order to make course content attractive and accessible to the Ss and Ts, an LMS should facilitate content management. The subcategories for this criterion are: creating a user-friendly and accessible interface, archiving after the end of a semester, importing/exporting/uploading content to 
use and reuse after a semester ends, and publishing and scheduling material in advance.

\subsection{Assessment and feedback}

Ts pursue the following features when they are assessing student performance: the ability to import/export quizzes from one class to another or from a previous semester to a new one, the presence of a question bank that covers a variety of options for creating questions, automatic grading, and a nongrading option. An LMS should be able to provide different alternatives for the provision of assessments to the whole class or to a certain number of Ss within class, supplying different submission formats (file, video, audio, link, etc.), and setting flexible deadline with the option of deducting grades in the case of late submission.

Concerning feedback, first, an LMS should have more than one correction tool depending on the nature of the assignment: grading on the interface itself, on the submitted document and then returning it back to the student, or audio/visual feedback. Second, it is preferable that the LMS provides an option of integrating a rubric in the assignment so that the teacher adds the feedback into each student's work. The rubric is particularly significant for writing or speaking assessments. Third, it is highly beneficial for the student to receive feedback linked to a previous assignment. Fourth, for the purpose of academic integrity, the LMS should have a means of providing or syncing with a plagiarism detection tool.

\subsection{Communication, collaboration, and synchronization}

Language education emphasises on collaboration and communication inside and outside the class. Polls give Ss the opportunity to have an active role and participate in decision-making to develop and/or adapt any of the course material. For EFL Ts, having the Ss practice English outside of the class is an integral part of language learning. This can be augmented by a monitored space for student-student and student-teacher discussions. At the same time, Ss should be able to communicate privately with the instructor. Other features include dividing Ss into groups for collaborative work, allowing them to add material to promote active learning, accessing the LMS on mobile devices, and syncing with other applications for assessment or plagiarism detection etc.

\subsection{Capacity}

This includes the capacity of the LMS, including memory and the number of classes and Ss per instructor. It is noteworthy when considering a free LMS for an English Department in a higher education institution.

Table 1. Score breakdown for the two LMSs

\begin{tabular}{|c|c|c|}
\hline Criteria & $\begin{array}{l}\text { Score } \\
\text { (C) }\end{array}$ & $\begin{array}{l}\text { Score } \\
\text { (GC) }\end{array}$ \\
\hline \multicolumn{3}{|c|}{ A. $\quad$ Class and Group Management } \\
\hline $\begin{array}{l}\text { 1. } \begin{array}{l}\text { Creating classes and } \\
\text { subgroups }\end{array} \\
\text { Sulp }\end{array}$ & 5 & 4 \\
\hline $\begin{array}{ll}\text { 2. Adding/removing Ss } \\
\text { and Ts }\end{array}$ & 5 & 3 \\
\hline 3. $\quad$ Notifications & 4 & 4 \\
\hline 4. $\quad$ Attendance & 5 & 1 \\
\hline 5. Calendar & 4 & 4 \\
\hline Total: & 23 & 18 \\
\hline \multicolumn{3}{|l|}{ B. Content Management } \\
\hline 1. Interface & 3 & 5 \\
\hline 2. $\quad$ Archiving & 2 & 5 \\
\hline 3. Material management & 4 & 4.3 \\
\hline $\begin{array}{l}\text { 4. Importing/exporting/ } \\
\text { content }\end{array}$ & 4 & 5 \\
\hline Total: & 14 & 19 \\
\hline \multicolumn{3}{|c|}{ C. Assessment and Feedback } \\
\hline 1. Quizzes & 5 & 3 \\
\hline 2. Question bank & 5 & 1 \\
\hline 3. $\quad$ Grading & 5 & 2 \\
\hline $\begin{array}{l}\text { 1. Assignments } \\
\text { a)Assigning }\end{array}$ & 5 & 4 \\
\hline b) Submission Format & 5 & 1 \\
\hline c) Deadlines/ deduction policies & 3 & 3 \\
\hline \multicolumn{3}{|l|}{ Feedback } \\
\hline a. Correction tools & 5 & 3 \\
\hline b. Uploading rubric & 5 & 1 \\
\hline $\begin{array}{l}\text { c. linking feedback to previously } \\
\text { taught material }\end{array}$ & 4 & 5 \\
\hline d. Plagiarism detection & 5 & 1 \\
\hline Total: & 47 & 24 \\
\hline \multicolumn{3}{|c|}{$\begin{array}{l}\text { D. Communication, Collaboration, anc } \\
\text { Synchronization }\end{array}$} \\
\hline 1. Polls & 4 & 5 \\
\hline 2. Discussions/Interaction & 5 & 2 \\
\hline 3. $\quad$ Private messages & 5 & 4 \\
\hline 4. $\quad$ Collaborative work & 5 & 3 \\
\hline 5. $\begin{array}{l}\text { Students can add } \\
\text { material }\end{array}$ & 4 & 5 \\
\hline 6. $\quad$ Mobile-friendly & 5 & 4 \\
\hline $\begin{array}{ll}\text { 7. } & \text { Synchronizing } \\
\text { other websites }\end{array}$ & 5 & 4 \\
\hline Total & 33 & 27 \\
\hline E. Capacity & 3 & 5 \\
\hline Grand Total: & 120 & 93 \\
\hline
\end{tabular}




\section{Results and Discussion}

The overall results of the comparison showed the precedence of C (120 pts) over GC (91 pts) (see table 1 below for rubric and detailed breakdown of scores). GC scored higher in two criteria: content management and capacity; $\mathrm{C}$, on the other hand, proved to be more beneficial for the instructors in the other three criteria: class and group management; assessment and feedback; and communication, collaboration, and synchronization.

\subsection{Class and Group Management}

In class and group management, $\mathrm{C}$ scored slightly higher than GC. It was easy to create a class in the two LMSs with just a few steps. However, in C, Ts could create multiple sections for the same class/course and easily move Ss across them, which was not possible in GC. Both LMSs allowed for adding co-teachers with full access to the class, but $\mathrm{C}$ offered the option of giving defined roles for coteachers, TAs, and observers. Adding/removing Ss was simple in the two LMSs. In both LMSs, Ts and Ss were instantly notified (via email and/or the mobile application) of all the new assignments, posts, etc., but they were not sent reminders before deadlines or important dates, and they could not customize the notifications they received. Attendance tracking was available in C, and Ss got notified of their absences, but this feature was not available in GC. C had an integrated calendar that sent notifications to $\mathrm{Ss}$ and Ts with important dates and deadlines; GC used Google Calendar. The two LMSs saved the Ts' time and facilitated collaboration between the co-teachers and course coordinators in tracking the number of registered Ss, their attendance, completed assignments, and submissions.

\subsection{Content Management}

As for content management, GC surpassed $\mathrm{C}$ in its simplicity and usability. C's interface was complicated (16 tabs) and required an orientation in class, while GC had only three tabs. Archiving was available in the two LMSs. However, in order to keep an archive of old assignments in C, Ts had to download them on a desktop computer or CD. Material in both LMSs could be uploaded in any format or synced with Google Drive in GC. When it comes to arranging the material, $\mathrm{C}$ had the options of arranging, scheduling, and posting the material as per the Ts' preferences, while GC only allowed arranging the material such that the newly added material were posted instantly with the most recent on top in the About tab. The two LMSs facilitated sharing and editing documents and allowed specifying whether the Ss can view, edit or comment on the shared documents. The ease of archiving and sharing class material with the Ss saved time and made the material appealing and accessible to them.

\subsection{Assessment and Feedback}

Assessment and feedback is one of the main criteria that showed a big difference between the two LMSs. C allowed the Ts to create a question bank with a variety of question types, while GC did not. As for grading, $\mathrm{C}$ provided the $\mathrm{Ts}$ with a comprehensive gradebook that showed Ss' graded and ungraded assignments in numbers (with decimals) or in percentages. GC had a less developed gradebook that was not convenient for the Ts. Assigning assessments was easy in the two LMSs, providing the Ts with the options of instantly posting or scheduling the assignments, in addition to adding deadline and description for each assignment, and its weight. However, $\mathrm{C}$ had a further option that allowed the Ts to assign assessments to specific Ss if they had a make-up quiz or assignment. Ts could see submissions and late submissions' dates and times, but deductions could only be made manually by the Ts. In C, Ss could submit assignments in different formats (documents, videos, podcasts, etc.), while GC only allowed Ss to submit the assignments as documents in any google format (doc, excel, etc.).

Giving feedback on Ss' work was more efficient in $\mathrm{C}$ than in GC. Ts could provide written feedback (with a variety of correction tools) or oral feedback. Ts could also upload or create rubrics to help the Ss identify their strengths and weaknesses against the assessment criteria on the rubric. GC allowed writing comments on selected highlighted parts of the assignments with no rubric or easy-to-use correction tools. Both LMSs allowed the Ts to link feedback to previously taught material. Plagiarism detection options were only present in $\mathrm{C}$ by syncing with Turnitin, but were absent in GC. C and GC made it easy for the $\mathrm{Ts}$ to track the $\mathrm{Ss}$ ' progress and performance and pinpoint their strengths and weaknesses and possible strategies to cater for their needs in a more personalized manner.

\subsection{Communication, Collaboration, and Synchronization}

In that context, $\mathrm{C}$ provided a more convenient communication and collaboration space for S-T, S-S and $\mathrm{S}$-material interaction as proposed in [6]. $\mathrm{C}$ had three more advanced features than GC: discussions, private messages, and group projects. The Ts could initiate whole class discussions, and the Ss could share their e-portfolios with other Ss. The Ts could contact the Ss easily and instantly through private messages. Moreover, the Ts could add Ss to group projects, divide the work between them, and track their progress. The Ss had the option to share 
material with the class. Although GC provided the shared document options, $\mathrm{C}$ made it easier for the Ts to manage group work and facilitated different forms of communication. The two LMSs are mobilefriendly and $\mathrm{C}$ can sync with a number of other websites and applications.

\subsection{Capacity}

Although $\mathrm{C}$ seemed more solid in many aspects and encouraged the researchers to use it in more than one course, the small capacity of the free version was the main reason why the researchers resorted to GC as an alternative in classes with bigger number of $\mathrm{Ss}$ and assignments. C has only a $250 \mathrm{MB}$ capacity, while GC has unlimited capacity for institutional accounts and $30 \mathrm{~GB}$ capacity for all the $G$ suite products of the personal accounts.

Having both advantages and disadvantages, the two LMSs aided the Ts in creating an active, BL environment that helped the Ts make the best use of their time and fostered smooth and frequent communication between them and the Ss inside and outside class. They also supplemented the Ts' efforts inside the class with accessible and appealing material that Ss can go through at their own pace. Furthermore, they allowed the Ts to provide better feedback and differentiated support to Ss of different abilities and progress levels. Furthermore, the two LMSs helped in having a paperless semester, where all the material, announcements, submissions, and feedback comments were exchanged electronically in a safe, easy and organized way. On top of all, $\mathrm{C}$ and GC encouraged the Ss to have some control over their own learning and made them more engaged, motivated, and autonomous. This was evident in Ss' comments in the course evaluation forms at the end of the semester. Thus, the current study demonstrates how Ts can use LMSs in making the best use of the advantages of BL [11], even in underprivileged countries.

In the same line of research, [12] investigated how factors such as Information Technology (IT) infrastructure and cultural characteristics highly influence the acceptance and diffusion of LMSs as an instructional tool in the developing country of Jordan. The researchers traced the behavioural intent represented in the relative advantage, complexity, compatibility of, and attitude towards LMSs. In spite of the fact that they accentuated how integrating an LMS is affected positively by IT infrastructure and cultural characteristics factors differing from those investigated in the present study, they emphasized how their results can be generalized to administrators, Ss, and instructors only at Jordanian universities and how their research instruments can be applicable only in similar contexts. Nevertheless, the present study provides a more generic rubric that can be used by any administrator, student, and instructor in any economically disadvantaged country as long as a strong internet connection is catered for. Accordingly, it can be concluded how both the generic rubric introduced here together with the two factors of IT infrastructure and cultural characteristics presented by [12] all play an integral part of selecting a suitable open-source LMS for the EFL classroom in disadvantaged countries.

\subsection{Recent Updates in GC}

While the researchers' comparison has shown that $\mathrm{C}$ has more sophisticated features that could facilitate Ts' work, it is worth mentioning that $\mathrm{GC}$ is successfully striving to regularly introduce new features and updates based on users' feedback, comments, and requests. This, in turn, would make GC with its simplicity and unlimited storage a stronger competitor in the near future.

Based on the researchers' criteria, GC's new updates have provided solutions for some of the downsides discussed earlier in the study in 2017 and/or options that address some minor inconveniences that affect users' experience with the LMS. In class and group management, GC now allows class ownership transfer between Ts. This could be useful if one teacher changes the class he/she teaches or leaves the school or institution for any reason, keeping the class safe and usable by other Ts. It also allows Ts to reorder their class cards according to their preferences. In content management, GC provides Ts with the option of using the Google bar, making the access to Google Drive material easier than before. In addition, Ts are allowed to add drive materials that they do not have permission to share. In assessment and feedback, it is possible for Ts to see a single view of a student's work to easily track his progress. It has also become possible to post an assignment to a specific student's page in case of make-up assignments and/or differentiated assessments. Moreover, Ts can now add decimal grades, a feature that was missing in the older versions of the LMS. Additionally, Ts can import Google Forms quiz grades to Ss' work page and return them to Ss automatically. It is also worth mentioning that GC has become available for personal accounts with the same features but with limitations on: the number of classes a teacher can create (30/day), classes a teacher can join (100 max), class size (250 members for both Ts and Ss), and class-member invitations a teacher can send (100 per class/per day) [13].

\section{Conclusion}

In spite of the limited number of Ss who used the two LMSs, it is noteworthy to state how the researchers' hands-on experience as course coordinators allowed for a wider scope of the course, 
material, teacher, and student management. However, a survey distributed to other EFL Ts teaching different English courses while using the LMSs would have added more insights into the results and discussion.

It is recommended that EFL instructors integrate the use of LMSs in all EFL classrooms, even in underprivileged countries. Ts can select the suitable LMS based on their needs; those who seek a large capacity can make use of GC and those who advocate more sophisticated options can use $C$.

Furthermore, LMS developers are required to add more EFL-oriented options to assist any EFL instructor, especially when it comes to assessment, feedback and communication. Last but not least, future studies should be conducted to further assess how far LMSs could foster learner autonomy in such learning environments.

\section{References}

[1] D. Bath and J. Borke, "Blended learning in Griffith University", Getting Started with Blended Learning, Griffith University, Griffith Institute for Higher Education, 2010, Ch. 1, p. 1.

[2] E. Dahlstrom, D.C. Brooks, and J. Bichsel, The Current Ecosystem of Learning Management Systems in Higher Education: Student, Faculty, and IT Perspectives. Research report, Louisville, CO: ECA, 2014, from: http://www.educause.edu/ecar [Accessed: 20-July-2017].

[3] A. Abdul Kadir, and N. Aziz, "Learning Management System of Higher Education Institution", Indian Journal of Science and Technology, 9 (9), 2016, pp. 1-5.

[4] M. Szabo, and K. Flesher, CMI theory and practice: Historical roots of learning management systems. Paper presented at the E-Learn 2002 World Conference on ELearning in Corporate, Government, Healthcare, \& Higher Education, Montreal, Canada, 2002, pp. 929-936.

[5] S. Lonna, and S. Teasley, "Saving Time or Innovating Practice: Investigating Perceptions and Uses of Learning Management Systems", Computers \& Education, 53, pp. 686-694.

[6] A. AbouRezk, "Using Blended Learning Strategies in the EFL classes: The Effect of an Online Course on the College Students' Speaking", Educational Sciences Journal, 2015, 23 (1), pp. 1-43.

[7] B. M. Wright, "Blended Learning: Student Perception of Face-to-Face and Online EFL Lessons", Indonesian Journal of Applied Linguistics, 2017, 7 (1), pp. 64-71.

[8] N., Emelyanova, and E. Voronina, "Introducing Blended Learning in the English Language Classroom: Students' Attitudes and Perceptions Before and After the Course", Knowledge Management \& E-Learning, 2017, 9 (1), pp. 33-49.
[9] S. Pusuluri, A. Mahasneh, and B. Alsayer, "The Application of Blackboard in the English Courses at $\mathrm{Al}$ Jouf University: Perceptions of Students", Theory and Practice in Language Studies, 2017, 7 (2), pp. 106-111.

[10] V. M. Ramesh, and C. Ramanathan, "A Rubric to Evaluate Learning Management Systems", Teaching, Assessment and Learning for Engineering (TALE), 2013 IEEE International Conference, pp. 73-77.

[11] K. Gotovsky, C. Lee, J. Bhimani, K. Ding, M. Vahed, R. Hossain, R. Min, R. Yu, S. Javed, and T. Nguyen, The Future of Blended Learning: A Report for Students and Policy Makers, Ontario, The Federation of the Canadian Secondary Students, 2017, Accessed from: https://static1.s quarespace.com/static/53c2060ae4b0db3d3fa5937f/t/591ca 78f6a49632377fa8fd5/1495050128097/Future+of+Blende d+Learning.pdf [Accessed: 20-July-2017]

[12] A. Al Amoush and K. Sandhu, "Factors in the acceptance of an LMS in Jordanian universities", Asia Pacific Journal of Contemporary Education and Communication Technology, 4 (1), 2018, pp. 161-170, Accessed from: https://apiar.org.au/?journal-paper=factorsin-the-acceptance-of-an-lms-in-jordanian-universities [Accessed: 23-February-2018]

[13] "What's New in Classroom", Accessed from: https://support.google.com/edu/classroom/answer/6149237 ?hl=en [Accessed: 24-February-2018] 